\title{
A construção da desinformação - \\ uma análise da formação de professores e sua abordagem quanto às novas tecnologias educacionais
}

\section{Vanessa Zinderski Guirado ${ }^{1}$}

\section{RESUMO}

O presente artigo faz uma análise acerca de uma questão em contínua construção, ou até desconstrução, como parece acontecer muitas vezes, em virtude da fragmentação dos conteúdos programáticos e da falta de propriedade com que as questões tecnológicas são trabalhadas na escola, que é a formação de professores e o uso de novas tecnologias educacionais. Por mais que os nossos recursos tecnológicos estejam presentes por toda parte, em nosso dia a dia, há uma recusa e uma limitação por parte dos cursos de licenciatura em usar determinados recursos tecnológicos, e, em muitos casos, quando eles são empregados, tal ação é desenvolvida de maneira superficial, contribuindo para uma inversão, favorecendo a tecnologia em si, e não o aprendizado, que pode ser agregado a tal tecnologia, em um visível detrimento do ensino e uma supervalorização da informática como solução de todos os problemas educacionais.

Palavras-chave: Formação de Professores; Tecnologias Educacionais; Políticas Educacionais.

\begin{abstract}
This article is an analysis of an issue in ongoing construction or even deconstruction, as seems to happen often, because of the fragmentation of the syllabus and the lack of property with the technological issues are worked in the school, which is teacher training and the use of new educational technologies. As much as our technological resources are present everywhere in our day after day, there is a refusal and a limitation on the part of degree courses in using certain technological resources, and in many cases, when they are employed, such action is developed in a superficial way, contributing to a reversal and promoting the technology itself, and not the learning that can be added to such technology, in a visible detriment of education and computer science overvaluation as a solution to all educational problems.
\end{abstract}

Keywords: Teacher Training; Educational technologies; Educational policies. Mestranda do Programa de Pós-Graduação em Educação, Arte e História da Cultura da
Universidade Presbiteriana Mackenzie. E-mail: vanguirado@gmail.com 


\section{Tecnologia e formação de professores, duas realidades distintas na escola}

A questão da formação de professores sempre provocou grandes discussões quanto à escolha das disciplinas que poderiam representar um preparo profissional mais adequado do docente e, pelo menos nos últimos vinte e poucos anos, há uma crescente preocupação com a inclusão de novas tecnologias educacionais nos cursos de licenciatura. Tal preocupação decorre, entre outras coisas, principalmente de mudanças sociais e tecnológicas profundas, que ocorreram de maneira muito rápida. Por exemplo, Grande parte dos trabalhos que antigamente eram realizados de forma manual, passaram a ser exercidos com a ajuda de computadores.

As mudanças foram tão agressivas que, no Brasil, por exemplo, em um período relativamente muito curto, incorporamos a tecnologia móvel como obrigatória em nosso dia a dia. Esta relação com as novas tecnologias modificaram o ritmo das comunicações interpessoais, transformaram as dinâmicas das profissões e invadiram, não apenas todos os setores produtivos, como também a vida privada das pessoas.

Aúnica dissonância tecnológica frente ao digital mundo novo que temos hoje parece ser a escola, pois ela apresenta uma configuração muito semelhante a que apresentava quando de seu surgimento. Obviamente, se todo o mundo sofreu uma transformação e só um ambiente permanece praticamente inalterado, ao longo do tempo, há a tendência de ocorrer conflitos, que acabam por interferir no funcionamento deste, que no caso é a escola. Logo, tal interferência acaba sendo refletida na atuação do profissional da educação, o que nos leva a repensar a formação docente. E é pensando na discussão dessa formação profissional e nos conteúdos curriculares apresentados nos cursos de licenciatura que seguiremos na construção do presente trabalho.

\section{Formação de professores: dissonância e desinformação}

Quando analisamos a estrutura dos cursos de formação dos professores, nos deparamos com a lacuna existente entre o que dizem os textos legais e a prática formativa, pois quando fazemos uma análise dos Projetos Pedagógicos dos cursos, suas ementas e estruturas curriculares, constatamos a fragmentação que há na formação desse profissional, segundo Gatti (2013), a proporção de horas dedicadas às disciplinas referentes à formação profissional docente, nas licenciaturas em pedagogia fica em torno de $30 \%$, ficando $70 \%$ para outros tipos de matéria ou atividade e, nas demais licenciaturas, essa proporção fica entre $10 \%$ e $15 \%$ para as disciplinas da educação, e entre $85 \%$ e $90 \%$ para outras disciplinas ou atividades.

Se a situação de dissonância nos cursos de licenciatura já ocorre em uma questão tão básica como é a formação pedagógica do futuro professor, afinal, é imprescindível que o professor saiba como exercer o seu trabalho e tenha um arcabouço que o sustente nas questões pedagógicas e nos conteúdos específicos, no caso do uso de novas tecnologias educacionais, como suporte para o ensino das disciplinas, podemos dizer que tais práticas parecem coisa de filme futurista.

Formação básica torna-se mais estratégia que especialização profissional, já que o processo produtivo tem sua qualidade e 
competitividade condicionadas à capacidade de organização processual, prevenção de falhas, incremento qualitativo de processos e etapas, reinterpretação de situações, exigindo raciocínio analítico, habilidade e rapidez para processar informação e tomar decisões (DEMO, 2007, p. 24).

Os problemas iniciados na formação desse profissional, ainda se agravam com a sua entrada no mercado de trabalho, pois o contexto atual de exercício profissional é marcado pela dissonância e fragmentação dos conteúdos, do distanciamento das novas tecnologias enquanto recurso educativo, herdados de sua formação inicial, e ainda se depara com alunos com níveis diferentes de capacidades cognitivas, além de níveis diferentes de condições socioeconômicas.

Segundo Chauí (2001), em relação ao ensino superior, sua crise ultrapassa a questão das ações desenvolvidas, pois o seu impacto reflete diretamente na formação de um ser humano massificado, apático e facilmente manipulável.

(...) Creio que a universidade tem hoje um papel que alguns não querem desempenhar, mas que é determinante para a existência da própria universidade: criar incompetentes sociais e políticos, realizar com a cultura o que a empresa realiza com o trabalho, isto é, parcelar, fragmentar, limitar o conhecimento e impedir o pensamento, de modo a bloquear toda tentativa concreta de decisão, controle e participação, tanto no plano da produção material quanto no da produção intelectual. Se a universidade brasileira está em crise é simplesmente porque a reforma do ensino inverteu seu sentido e finalidade - em lugar de criar elites dirigentes, está destinada a adestrar mão-de-obra dócil para um mercado sempre incerto. E ela própria ainda não se sente bem treinada para isto, donde sua "crise" (CHAUÍ, 2001, p. 46).

Essa situação acaba sendo enfatizada pela estrutura de um sistema neoliberal e globalizado, o que contribui para o crescimento de outras realidades também dissonantes, que são: uma completa massificação do ensino, uma fragmentação ainda maior dos conteúdos, visando a englobar toda a diversidade do público frequentador da escola, mesclada à constante incorporação de novas demandas ao ambiente escolar, visto que não há instituições específicas para cuidar de questões que vão desde mudanças nas estruturas econômicas, culturais e sociais, que transitam do momento em que há a crescente inclusão da mulher no mercado de trabalho, que vem ocorrendo desde a década de 1930, até a mudança nas estruturas familiares ortodoxas e a referência de gênero, com casais homossexuais sendo pais e mães de crianças em período escolar.

E são muitas as causas implicadoras, que contribuem para que esse abismo seja ainda mais profundo, indo desde conceitos incorporados pela sociedade acerca do que é o papel do professor, gerando uma série de outras funções, muitas vezes impostas como 
deveres, que ultrapassam muito a relação de profissionalismo dessa categoria profissional.

Defendo hoje uma escola centrada na aprendizagem. Defendo mais:
uma separação, difícil de se fazer na realidade, entre o conceito de
escola e o conceito de espaço público da educação. Esses conceitos
estão neste momento confundidos. A educação é feita na escola, formal e
informal, a educação escolar e não-escolar, as atividades livres, lúdicas,
tempos livres. Há uma grande confusão, porque a escola "transbordou",
assumiu muitas missões, de tal maneira que os dois conceitos estão hoje
quase confundidos. Sempre que surge um novo problema, é votada uma
nova lei no parlamento e esse problema é lançado para dentro da escola
(NÓVOA, 2007, p. 07).

O professor ainda é assolado pelos problemas de identidade profissional, afinal, se fizermos uma análise de outras profissões, fica nítido que, de modo geral, elas possuem uma identidade bem definida, vemos isso nos advogados, engenheiros, médicos, que, aliás, para chegarem a ser reconhecidos como profissionais, passaram boa parte de suas vidas sendo instruídos e tutelados por professores, porém, no caso do professor, há uma identidade formada com lacunas e equívocos, gerando a fragmentação da profissão por níveis e títulos, reforçando ainda mais tal segmentação, pois por mais que existam diferenciações da função profissional, de acordo com o nível educacional de atuação do profissional, e por mais que seja compreensível que, dependendo do nível educacional de atuação, será necessário um maior aprofundamento nos estudos e que esse profissional qualificado deve ser remunerado de maneira adequada, nada pode justificar que a educação de base seja tratada de modo tão displicente, afinal, são nos primeiros anos de vida que a criança desenvolve a sua capacidade cognitiva, e formar mal esse profissional, ou remunerá-lo inadequadamente, pode comprometer não apenas as futuras gerações de professores, mas também as de médicos, engenheiros, advogados e qualquer outra profissão que certamente passará pelos bancos escolares.

85. Qualquer visão de vanguarda na educação e qualquer política adequada de ensino devem considerar o sistema de ensino como um todo. Portanto, qualquer reforma do ensino superior deve tomar em consideração sua estreita interdependência com todos os demais níveis de educação (UNESCO, 1999, p. 66 e 67).

Um outro problema enfrentado pelos profissionais de educação é o direcionamento de ações educacionais voltadas para as tendências mercadológicas e regulamentadas por instrumentos legais, inspirados no que ditam as agências internacionais. Acarretando uma educação superior pautada na demanda provocada por questões unicamente econômicas e políticas, ficando a questão educacional para segundo plano, implicando na distorção da função educacional, pois de educação ela vira mercadoria e, neste aspecto, quem tem o poder para ditar o que o mercado quer, acaba ditando as regras educacionais, visando a que estas sejam as mais convenientes possíveis para os seus interesses mercantis, 
políticos e econômicos, levando a educação a ser pensada em questões de custos versus benefícios, subvertendo a relação de aluno, em consumidor de produtos educacionais, possibilitando que o conhecimento seja preterido e o reconhecimento seja convalidado apenas pela obtenção de um título, sem considerar nem o valor do conhecimento nem o da obtenção de um título.

A transformação da educação superior numa mercadoria educacionaléumobjetivo delongo prazoeessehorizonteéessencial para compreender a intensificação da transnacionalização desse mercado atualmente em curso. Desde 2000, a transnacionalização neoliberal da universidade ocorre sob a égide da Organização Mundial do Comércio no âmbito do Acordo Geral sobre o Comércio de Serviços (GATS). A educação é um dos doze serviços abrangidos por este acordo e o objetivo deste é promover a liberalização do comércio de serviços através da eliminação, progressiva e sistemática, das barreiras comerciais. O GATS transformou-se em pouco tempo num dos temas mais polémicos da educação superior, envolvendo políticos, universitários e empresários. Os seus defensores veem nele a oportunidade para se ampliar e diversificar a oferta de educação e os modos de a transmitir de tal modo que se torna possível combinar ganho econômico com maior acesso à universidade. Esta oportunidade baseia-se nas seguintes condições: forte crescimento do mercado educacional nos últimos anos, um crescimento apenas travado pelas barreiras nacionais; difusão de meios eletrônicos de ensino e aprendizagem; necessidades de mão-de-obra qualificada que não estão a ser satisfeitas; aumento da mobilidade de estudantes, docentes e programas; incapacidade financeira de os governos satisfazerem a crescente procura de educação superior (SANTOS, 2011, p. 33 e 34).

Quando analisamos documentos da Unesco (1999), é possível identificar o direcionamento destinado ao ensino superior e à importância do mercado de trabalho, pois está posta a preocupação com a questão de preparar um profissional estruturado para um mundo em constantes mudanças, possibilitadas pela tecnologia, globalização, fragmentação e diversidade, exigindo que a universidade modifique a sua atitude frente às ações de ensino-aprendizagem.

VII. A necessidade de relevância adquire novas dimensões e maior urgência no instante em que as economias modernas solicitam graduados que possam constantemente pôr em dia seus conhecimentos, aprender novas habilidades, e que possuam as qualidades de ser não somente bons profissionais em busca de emprego, mas também criadores de empregos em mercados de 
trabalho mutantes. O ensino superior precisa repensar sua missão e redefinir muitas de suas funções, particularmente em vista da necessidade que a sociedade tem de pessoas com treinamento e conhecimentos em constante atualização (UNESCO, 1999, p. 13).

Lógico que, enquanto instituição social, não há como a escola ficar isolada e ignorar as demandas postas pelas necessidades do mercado, pois em um mundo em constante mutação, as profissões também não são estáticas, sofrem modificações, algumas são extintas e outras criadas, gerando a necessidade de criar novos cursos para atender às demandas do futuro profissional, bem como, preparar melhor seus alunos para sua vida futura, porém, isso não deve ser confundido com o mero surgimento de um novo produto educacional.

(...) o indivíduo é um consumidor de conhecimentos que o habilitam a uma competição produtiva e eficiente no mercado de trabalho. A possibilidade de obter uma inserção efetiva no mercado depende da capacidade do indivíduo em "consumir" aqueles conhecimentos que lhe garantam essa inserção (GENTILI, 2005, p. 55).

Frente a tantos desafios, é possível dizer que nenhum outro profissional tem que lidar diariamente com tantas instâncias diversas como o professor, pois ele atua sobre um material único, que é o potencial humano, em um mundo em constante modificação. Por sua vez, a sua ação também é pautada em seu próprio potencial enquanto ser humano, com todas as suas experiências, visões de mundo, concepções formativas e um arcabouço de informações que ultrapassam as questões escolares, integrando ética, moral, cultura e sociedade.

É preciso, sobretudo, e aí já vai um destes saberes indispensáveis, que o formando, desde o princípio mesmo de sua experiência formadora, assumindo-se como sujeito também da produção do saber, se convença definitivamente de que ensinar não é transferir conhecimento, mas criar as possibilidades para a sua produção ou a sua construção (...) Não há docência sem discência, as duas se explicam e seus sujeitos, apesar das diferenças que os conotam, não se reduzem à condição de objeto, um do outro. Quem ensina aprende ao ensinar e quem aprende ensina ao aprender. Quem ensina, ensina alguma coisa a alguém (FREIRE, 2002, p. 12).

É em meio a esse turbilhão de falsas acomodações de situações distintas e a construção de um cenário cheio de acúmulo de responsabilidades tanto para os cursos de licenciatura e suas instituições formativas, quanto para a profissão de professor, e a exoneração de responsabilidade com o futuro educacional das futuras gerações por 
parte do Estado e da sociedade, que vemos algumas diretrizes e iniciativas buscando ajustar o uso de novas tecnologias nos cursos de formação de professores, visando a uma adequação à realidade contemporânea e globalizada, a melhor formação desse profissional e a utilização das tecnologias educativas como recurso para melhorar e ampliar o ensino, e acabar com desigualdades.

\begin{abstract}
A pedagogia não pode ser outra coisa senão a prática de um profissional, isto é, de uma pessoa autônoma, guiada por uma ética do trabalho e confrontada diariamente com problemas para os quais não existem receitas prontas. Um profissional do ensino é alguém que deve habitar e construir seu próprio espaço pedagógico de trabalho, de acordo com limitações complexas que só ele pode assumir e resolver de maneira cotidiana, apoiado necessariamente em uma visão de mundo, de homem e de sociedade (TARDIF, 2000, p. 149).
\end{abstract}

\title{
Formação de professores e as novas tecnologias: uma questão em construção
}

As maiores dúvidas que surgem quando pensamos na Era Digital e na aplicação de novas tecnologias na educação são: "será que o uso do computador e de tais tecnologias digitais, empregadas nas salas de aula mudaram a forma de ensinar e aprender? Que temos acesso a uma infinidade de recursos nos dias atuais, isso é inegável, mas até onde a informática e o uso de recursos digitais são encarados como subterfúgios úteis ao ensino? E até onde a questão das novas tecnologias é usada de modo tão displicente, que acaba isolando a educação em uma redoma e contribui para um abismo digital entre as realidades de dentro e de fora?".

O que perturba avassaladoramente a universidade é que ela ainda não convenceu a sociedade de que poderia ser uma vanguarda educativa, científica e tecnológica. Ao invés disso, cristalizase como burocracia comum, perdida na guerra ordinária por vantagens e benefícios, em meio a uma decadência que já parece irrecuperável. Cada vez mais, vale menos a pena, não só em termos de gastos, mas também para os alunos (DEMO, 2007, p. 76).

Ao começar a análise deste tema polêmico, encontramos diversas vozes, postas em vários níveis, que resumiremos em duas: as ferozmente contra e as impetuosamente a favor. Mesmo sendo colocadas em dois amplos grupos, elas acabam por expor outras questões, pois é inevitável que em um mundo digital, a informática seja inserida no contexto educacional, porém ela não pode ser encarada como a solucionadora de todos os problemas nem como a finalidade maior dos trabalhos educacionais, afinal, quando tratamos de educação e de ensino, em seus aspectos mais amplos, estamos falando em conduzir o indivíduo às suas plenas capacidades intelectuais, morais e éticas, ou seja, levá- 
lo a ser um humano pleno capaz de discernir entre o certo e o errado, com competência de julgamento e escolha.

Entre as acusações de atraso em educação, uma das mais veementes foi a de Luhmann, que levantou a expressão "déficit tecnológico estrutural". (...) Vendo-se tecnologia como "a ciência das relações causais que subjazem às intenções práticas e pelas quais a ação deve orientar-se, se pretender êxito". (...) De outro lado, Luhmann rechaça o extremo oposto, que pretende subjugar educação à técnica, assumindo, como já é comum em certos ambientes positivistas (tipo Popper e Albert, cf. Demo, 1989), que não se sustenta a noção de causalidade estrita, mesmo para ciências naturais (DEMO, 2007, p. 13 e 14).

Tal tarefa é gigantesca e não há garantias de sucesso absoluto, pois, como elucidado anteriormente, as interferências ao trabalho educacional são enormes e seria ingenuidade acreditar que apenas com o uso de tecnologias digitais, tal objetivo seria mais facilmente direcionado, como também é descabido achar que apenas o trabalho do professor e o domínio das questões específicas da área e das diretrizes didáticas possa solucionar os problemas de ensino, afinal, como também especificado anteriormente, o material com que trabalhamos em educação é o humano, o que, por si só, encerra pequenos universos únicos, postos lado a lado em uma sala de aula.

Os saberes profissionais também são variados e heterogêneos porque não formam um repertório de conhecimentos unificado, por exemplo, em torno de uma disciplina, de uma tecnologia ou de uma concepção do ensino; eles são, antes, ecléticos e sincréticos. Um professor raramente tem uma teoria ou uma concepção unitária de sua prática; ao contrário, os professores utilizam muitas teorias, concepções e técnicas, conforme a necessidade, mesmo que pareçam contraditórias para os pesquisadores universitários. Sua relação com os saberes não é de busca de coerência, mas de utilização integrada no trabalho, em função de vários objetivos que procuram atingir simultaneamente (TARDIF, 2000, p. 14).

Logo, a solução seria a junção de todas as forças envolvidas, em prol da educação, porém, uma questão que parece tão lógica, não o é quando colocada em prática. Temos sim que inserir as novas tecnologias em nosso dia a dia escolar, mas sem esquecer todos os demais aspectos, pois mesmo estando socialmente inclusos em ambientes cada vez mais digitais, continuamos humanos e essa é uma característica absoluta que não devemos esquecer nem evitar.

A qualidade da educação escolar repousa na interação construída 
entre pessoas na intencionalidade de instruir(-se) e educar(-se). Ela não está no computador ou em qualquer objeto-meio. Ela repousa nas relações pedagógicas entre seres que buscam construir uma civilização. Ela se constitui nas mediações frutíferas que permitem a sequência dos conhecimentos e da busca por uma sociedade mais justa, em relações interpessoais, por onde perpassam os sentidos de uma civilização (GATTI, 2013, p. 58).

Ao analisar a LDB, Lei ${ }^{0}$ 9.394, de 20 de dezembro de 1996, que estabelece as diretrizes e bases da educação nacional, temos que a União ficou encarregada de direcionar as políticas públicas educacionais, conforme art. $8^{\circ}, \S 1^{\circ}$, que "caberá à União a coordenação da política nacional de educação, articulando os diferentes níveis e sistemas e exercendo função normativa, redistributiva e supletiva em relação às demais instâncias educacionais". Nesse documento, por ter sido promulgado em 1996, há poucas referências quanto ao uso de novas tecnologias, e essas estão restritas às questões de capacitação por meio de EaD. Podemos constatar isso no artigo 62, que teve a sua redação dada pela Lei $n^{\circ} 12.796$, de 2013, e os incisos 1, 2 e 3, incluídos pela Lei $n^{\circ} 12.056$, de 2009, que mesmo tendo sido redigidos anos mais tarde, mantiveram um distanciamento da questão das novas tecnologias educacionais.

Art. 62. A formação de docentes para atuar na educação básica far-se-á em nível superior, em curso de licenciatura, de graduação plena, em universidades e institutos superiores de educação, admitida, como formação mínima para o exercício do magistério na educação infantil e nos 5 (cinco) primeiros anos do ensino fundamental, a oferecida em nível médio na modalidade normal.

$\S 1^{\circ}$ A União, o Distrito Federal, os Estados e os Municípios, em regime de colaboração, deverão promover a formação inicial, a continuada e a capacitação dos profissionais de magistério.

$\S 2^{\circ}$ A formação continuada e a capacitação dos profissionais de magistério poderão utilizar recursos e tecnologias de educação a distância.

$\S 3^{\circ}$ A formação inicial de profissionais de magistério dará preferência ao ensino presencial, subsidiariamente fazendo uso de recursos e tecnologias de educação a distância (BRASIL, 2013, p. 20).

Quando analisamos o Plano Nacional de Educação, aprovado pela Lei no 13.005, de 25 de junho de 2014, com vigência administrativa para os próximos dez anos, a partir da data de sua publicação, identificamos no anexo, intitulado Metas e Estratégias, uma amplitude quanto ao assunto e há uma série de ações destinadas à questão de tecnologias voltadas para a educação, e, especificamente no item 15.6, há referência quanto à promoção de uma reforma curricular dos cursos de licenciatura, visando, entre outros, a inclusão de 
tecnologias de informação e comunicação em tal reformulação.

15.6) promover a reforma curricular dos cursos de licenciatura e estimular a renovação pedagógica, de forma a assegurar o foco no aprendizado do aluno (a), dividindo a carga horária em formação geral, formação na área do saber e didática específica e incorporando as modernas tecnologias de informação e comunicação, em articulação com a base nacional comum dos currículos da educação básica, de que tratam as estratégias 2.1, 2.2, 3.2 e 3.3 deste PNE (BRASIL, PNE, 2014, p. 13).

Para verificar a real situação das tecnologias educacionais, analisamos os cursos de Licenciatura em Letras, Matemática, Geografia e Química, do IFSP (Instituto Federal de Educação, Ciência e Tecnologia de São Paulo) - Campus São Paulo, da Ufscar (Universidade Federal de São Carlos), da USP (Universidade de São Paulo) e da Unicamp (Universidade de Campinas), com base nos Projetos Pedagógicos dos Cursos, nas Ementas das Disciplinas e nas Estruturas Curriculares disponíveis nos respectivos sites institucionais. Constatamos que existem disciplinas que contemplam o uso da informática e de tecnologias digitais, porém, quando analisamos melhor as ementas das respectivas disciplinas, fica claro o distanciamento existente entre currículo e prática, pois a tecnologia é apresentada de forma fragmentada, quando na realidade, deveria perpassar todo o curso, favorecendo o seu domínio e uso efetivo por parte dos futuros professores.

Com efeito, o valor social, cultural e epistemológico dos saberes reside em sua capacidade de renovação constante, e a formação com base nos saberes estabelecidos não passa de uma introdução às tarefas cognitivas consideradas essenciais e assumidas pela comunidade científica em exercício. Os processos de aquisição e aprendizagem dos saberes ficam, assim, subordinados material e ideologicamente às atividades de produção de novos conhecimentos. Essa lógica da produção parece reger também os saberes técnicos, bastante voltados, atualmente, para a pesquisa e para a produção de artefatos e de novos procedimentos (TARDIF, 2000, p. 34).

Ao analisar os cursos de Licenciatura em Letras, constatamos que, com exceção da USP, as demais universidades apresentam em seus cursos algum tipo de disciplina que envolva ou o uso de computação, ou de novas tecnologias de informação. Porém, tais disciplinas são oferecidas em algum momento específico dos cursos, favorecendo o distanciamento dos recursos tecnológicos da prática em sala de aula, consequentemente, levando o recém-formado a não ter familiaridade com esses recursos, favorecendo a não utilização deles por toda uma vida profissional, visto que será necessário que o novo professor tenha condições de perceber a potencialidade dos recursos digitais em sua 
prática, o que, por sua vez, necessitará de uma apropriação de novos conhecimentos e desenvolvimentos práticos para realizá-lo.

Os saberes profissionais também são temporais no sentido de que os primeiros anos de prática profissional são decisivos na aquisição do sentimento de competência e no estabelecimento das rotinas de trabalho, ou seja, na estruturação da prática profissional (TARDIF, 2000, p. 14).

Ao analisar os cursos de Licenciatura em Matemática, constatamos que todas as instituições apresentam em seus cursos disciplinas relacionadas ao uso de informática. Porém, mesmo aparentemente oferecendo o uso dos recursos tecnológicos de maneira mais ampla, permanece o problema do emprego desses em momentos específicos dos cursos, novamente favorecendo a fragmentação e o distanciamento dos recursos tecnológicos. Uma outra questão identificada, que possivelmente também acontece nas demais licenciaturas em diferentes níveis, é o fato de que em todas as disciplinas das Licenciaturas em Matemática analisadas, que envolvem tecnologias, existe a efetiva utilização de programas computacionais para cálculos algébricos e aproximados, visualizações gráficas e experimentos computacionais, porém não há especificação se o processo apenas ensina o aluno a utilizar o programa como um usuário, ou se também contextualiza o seu emprego para que o futuro professor possa realmente empregar tais aprendizagens e ensinar como empregar o programa em sala de aula, no seu dia a dia e no desenvolvimento de sua profissão, de fato, contribuindo para a superação das barreiras tecnológicas atuais.

Em ambientes virtuais não precisamos de quem dê aula, mas de quem oriente e avalie, acompanhe e motive, dialogue e questione. O professor, longe de pretender saber tudo, faz o papel de "coach": orquestra habilidades, compõe interesses, lidera processos, ativa dinâmicas. Não facilita, encurta, rebaixa. Ao contrário, eleva os desafios, sempre (...) A diferença social continua a mesma entre aluno e professor, mas, em termos de aprendizagem, é apenas questão de etapa: o professor está lá na frente, o aluno vem atrás, na mesma trilha (DEMO, 2009, p. 70).

Ao analisar os cursos de Licenciatura em Geografia, novamente vemos a reincidência das questões apontadas anteriormente. Assim como nos Cursos de Licenciatura em Matemática, a Geografia utiliza recursos e programas diversos durante a formação dos futuros professores, porém, mais uma vez, não há especificação se tal processo apenas ensina o aluno como utilizar os programas em um nível de usuário, ou se contextualiza o seu emprego para que ele possa ser empregado como instrumento válido em sala de aula. Vale ressaltar que o momento mais propício para mostrar todas as possibilidades de direcionamento de uma aula boa e bem estruturada, com oportunidades 
de emprego de conceitos específicos, pedagógicos e tecnológicos, é exatamente durante a graduação, quando os futuros professores possuem apenas parte da perspectiva educacional, relacionadas às suas visões e experiências como alunos, e ainda não foram totalmente contaminados com as dificuldades que a educação apresenta em nosso país.

É melhor definir o professor como "aprendiz" ("eterno aprendiz"). Assume aprendizagem como profissão e encaixa em sua profissão o compromisso de fazer outros aprenderem também. Os novos tempos acarretam novos reptos, entre eles saber desconstruir-se de maneira permanente, para ressuscitar todos os dias. Professor acabado é algo fútil. Manter-se aprendendo sempre é sua glória, mais que sua sina. Tem o compromisso de trazer para o aluno o que há de melhor no mundo do conhecimento e da tecnologia, para poder aprimorar sempre as oportunidades de aprender. Ao mesmo tempo, precisa saber aprender de muitas circunstâncias, não apenas de uma teoria isolada, de alguns autores fechados, de certas posições consideradas intocáveis. Nada é mais "tocável” que conhecimento, que, no fundo, é uma metamorfose ambulante (DEMO, 2009, p. 71).

Ao analisar os cursos de Licenciatura em Química, mais uma vez, identificamos a reprodução das questões apresentadas anteriormente. Contribuindo para que a análise desenvolvida conclua que há, de fato, uma separação entre a educação e as tecnologias, favorecendo ainda mais para o fortalecimento dessa cisão, gerando um abismo ainda maior entre as multiformações a que estamos expostos em um ambiente globalizado e tecnológico. Levando à formação de professores e, consequentemente, às universidades (ambientes formativos) e às escolas (ambientes de trabalho) a seguir em uma contradição e dissonância com os rumos que a sociedade segue, pois em todos os outros campos profissionais há uma agregação da tecnologia, no intuito de que esta contribua para a área, sem no entanto haver questionamento da finalidade da área e da supremacia tecnológica. Temos de nos posicionar a favor do ensino e deixar claro que a tecnologia pode sim ser somada aos recursos educacionais de forma integradora, pois nenhum desenvolvimento tecnológico pode ser capaz de substituir a importância do aprendizado e o papel fundamental do professor, como direcionador do ensino.

O futuro depende mais da nossa escolha de instituições que incentivem uma vida de ação do que do nosso desenvolvimento de novas ideologias e tecnologias. Precisamos de um conjunto de critérios que nos permitirá reconhecer aquelas instituições que favorecem o crescimento pessoal em vez de simples acréscimos. Precisamos também ter a vontade de investir nossos recursos tecnológicos, de preferência nessas instituições promotoras do crescimento pessoal (ILLICH, 1985, p. 65). 
A realidade da maioria das escolas brasileiras também não favorece que os professores venham a integrar novas tecnologias de informação em suas aulas, tanto pela falta de equipamentos e recursos, quando pela cultura de não entender o uso de recursos tais como, por exemplo, computador, vídeos e internet, como sendo parte de uma aula, perpetuando-se uma situação do que poderíamos chamar de apatia digital educacional, tanto por parte de instituições, quanto de professores e de alunos.

(...) as novas tecnologias não inventaram a aprendizagem. Por mais que induzam inovações, por vezes espetaculares, os legados anteriores não são apagados. São, antes, re-significados. Como a própria noção de remix sugere, toda ideia nova tem antecedente e conseqeente, não ocorrendo nunca ruptura cabal. Criar do nada é coisa que a natureza desconhece. A natureza propriamente "recria". Este reconhecimento, porém, não sugere que o fenômeno fundamental seja continuidade, pela simples razão de que só permanece o que muda (Massumi, 2002). Ao mesmo tempo, é crucial entender que novas tecnologias não supõem aprendizagens mais efetivas automaticamente. Podem facilmente servir para aprender menos ou não aprender. No entanto, guardam enorme potencialidade, se as soubermos vivificar (DEMO, 2009, p. 61).

Como já falamos anteriormente, as tecnologias educacionais não devem ser um fim e sim um meio que favoreça o ensino e o aprendizado, para tanto é imprescindível que a tecnologia, como especifica Candau (1979), seja um instrumento de busca da relevância, sendo necessário que continuamente se coloquem questões relativas ao "para quem", ao "para que" e ao "porquê" de sua contribuição à análise e solução dos problemas educacionais.

\begin{abstract}
Afirmar que a Tecnologia Educacional está inserida no âmbito da educação implica em que a Tecnologia não poderá encarar a educação como simples matéria a sofrer um tratamento tecnológico, mas, pelo contrário, é a tecnologia que deverá sofrer um tratamento educacional que informará toda a sua realidade. Assim sendo, os fins da educação deverão ser os norteadores da Tecnologia Educacional. Esta afirmação significa também postular que os problemas da preparação de recursos humanos e de currículo em Tecnologia Educacional devem ser integrados no contexto das questões relativas a recursos humanos e currículo em educação (CANDAU, 1979, p. 62).
\end{abstract}

Outra questão carente de mudança é a da visão cultural que as tecnologias educacionais exercem frente à sociedade, pois enquanto elas forem encaradas como subterfúgios para não ter aula, ou como recursos empregados por professores que não 
querem dar aula, será perpetuada uma significação inadequada do potencial envolvido no uso de tais tecnologias.

Se as novas tecnologias não inventaram a aprendizagem, trouxeram, por outra, muitas novidades úteis à aprendizagem. A primeira é a noção de "aprendizagens" ou de "multialfabetizações" (COPE/KALANTZIS, 2000), ou, ainda de "discurso multimodal" (KRESS/LEEUWEN, 2001) (DEMO, 2009, p. 62).

O avanço das tecnologias é inevitável, como também é inevitável que pensemos os currículos dos Cursos de Licenciatura de uma maneira mais integrada, buscando atingir conhecimentos múltiplos, para um mundo cada vez mais facetado.

Para a atividade profissional do professor, é imprescindível que ele tenha domínio técnico de sua área, que domine as técnicas e conhecimentos pedagógicos e que acompanhe as novas tecnologias educacionais, pois assim ele estará mais bem preparado para enfrentar os desafios postos à educação. Cabe, portanto, uma reflexão acerca do perfil profissional e da identidade do professor, fazendo com que esse profissional tenha a oportunidade de tantos outros que são formados por ele, a chance de se desenvolver, de participar e transformar a educação.

É desesperante ver certos professores que têm genuinamente uma enorme vontade de fazer de outro modo e não sabem como. Têm o corpo e a cabeça cheios de teoria, de livros, de teses, de autores, mas não sabem como aquilo tudo se transforma em prática, como aquilo tudo se organiza numa prática coerente (NÓVOA, 2007, p. 14).

\section{Conclusão}

Demo (2000), diz que desinformar faz parte da informação, assim como a sombra faz parte da luz, e que desinformar será, portanto, parte fundamental do processo de informação. Podemos fazer um paralelo do processo de desinformação com relação a questão das novas tecnologias educacionais nos currículos dos Cursos de Licenciatura, pois há disciplinas voltadas ao ensino das tecnologias, porém tal formação está fragmentada a pequenos espaços formativos dentro de determinadas disciplinas, não permeando a integração e uso delas, em sua total potencialidade de recursos disponíveis ao ensino e à aprendizagem. Ou seja, há a informação e ela é veiculada, mas ela não é integradora e contribui para o fortalecimento da desinformação.

Devemos ainda atentar para o fato do professor não ser uma ilha, afinal, por mais que ele seja o direcionador de suas aulas, há toda uma estrutura educacional, formada pelas instituições que o licenciam como professor, que possibilitam o seu desenvolvimento constante, por meio de cursos de extensão e pós-graduação. Há ainda a estrutura de trabalho, que também faz parte da educacional, que favorece ou desestimula o seu 
desempenho, por meio de ações governamentais de Políticas Públicas, ou econômicomercantil, visando atender ao mercado, que por sua vez reflete o comprometimento que a sociedade, como um todo, tem com a educação.

Mesmo com o uso diário de diversos recursos tecnológicos por parte da sociedade, em praticamente todas as faixas etárias, a questão ainda tem muito para avançar, quando pensamos em formação de professores, pois nos cursos de Licenciaturas, vemos a reprodução de disciplinas nitidamente voltadas para a ênfase na área de conhecimento específico, deixando para segundo plano a questão pedagógica e para, praticamente, último plano, a questão do emprego de novas tecnologias educacionais. Acabamos constatando que: em tempos de multidisciplinaridade, interdisciplinaridade e transdisciplinaridade, vemos que o que ainda dita as regras é a disciplinaridade.

\section{Referências}

BRASIL. Lei no 9.394, de 20 de dezembro de 1996. (1996). Diretrizes e bases da educação nacional - LDB. Disponível em: $\leq$ http://www.planalto.gov.br/ccivil_03/Leis/L9394. htm>. Acesso em: 15 mai. 2015.

Lei no. LEI No 12.796, de 04 de abril de 2013. (2013) Disponível em: http:// www.planalto.gov.br/ccivil_03/ato2011-2014/2013/lei/112796.htm. Acesso em: 15 de maio de 2015.

. Lei n ${ }^{\circ} 13.005$, de 25 de junho de 2014. (2014). PNE - Plano Nacional de Educação. Disponível em: $\leq$ http://www.planalto.gov.br/CCIVIL_03/_Ato2011-2014/2014/Lei/ L13005.htm>. Acesso em: 15 mai. 2015.

CANDAU, V. M. F. “Tecnologia Educacional: concepções e desafios”. In: Cadernos de Pesquisa, São Paulo, nº 28, p. 61-66, 1979.

CHAUÍ, M. Escritos sobre a Universidade. São Paulo: Editora Unesp, 2001.

COPE, B. \& KALANTZIS, M. Multiliteracies - Literacy learning and the design of social futures. New York: Routledge, 2000.

DEMO, P. Desafios modernos da educação. 14 ${ }^{\mathrm{a}}$ ed. Petrópolis, RJ: Vozes, 2007.

. "Aprendizagens e novas tecnologias". In: Revista Brasileira de Docência,

Ensino e Pesquisa em Educação Física, vol. 1, no 1, p. 53-75, Agosto/2009.

Ambivalências da sociedade da informação. Brasília: Ci. Inf. v. 29, nº 2, p. 37-42, maio/ago. 2000.

FREIRE, P. Pedagogia da autonomia: saberes necessários à pratica educativa. Paz e Terra. São Paulo, 2002.

GATTI, B. A. "Os professores e suas identidades: o desvelamento da heterogeneidade". São Paulo: Caderno de Pesquisa, nº 98, p. 85-90, ago. 1996. 
. Educação, escola e formação de profesores.In: Educar em

Revista, Curitiba, Brasil, no 50, p. 51-67, out./dez. 2013.

GATTI, B. A; ANDRÉ, M. E. D. de A; BARRETO, E. S. de S. Políticas docentes no Brasil: um estado da arte. Brasília: Unesco, 2011.

GENTILI, P. Três teses sobre a relação trabalho e educação em tempos neoliberais. In: LOMBARDI, J. et al. (Orgs.) Capitalismo, Trabalho e Educação. Campinas, SP: Autores Associados, 2002.

ILLICH, I. Sociedade sem escolas. Petrópolis, RJ: Vozes, 1985.

NÓVOA, A. Professores: imagens do futuro presente. Lisboa (Pt): Educa, 2009

Desafios do trabalho do professor no mundo contemporâneo. São

Paulo: Sinpro-SP, 2007.

SANTOS, B. de S. A universidade no século XXI: para uma reforma democrática e emancipatória da universidade. $3^{\mathrm{a}}$ ed. São Paulo: Cortez, 2011.

SAVIANI, D.; SANFELICE, J; L.; LOMBARDI, J; C. (orgs.). Capitalismo, Trabalho e Educação. 3. ed. Campinas, SP: Autores Associados, Histedbr, 2005.

TARDIF, M. Saberes docentes e formação profissional. Petrópolis: Vozes, 2000.

. "Saberes profissionais dos professores e conhecimentos universitários

- elementos para uma epistemologia da prática profissional dos professores e suas consequências em relação à formação para o magistério". In: Revista Brasileira de Educação, São Paulo, nº 13, jan./fev./mar./abr., 2000.

UNESCO. Política de mudança e desenvolvimento no ensino superior (tradução e revisão Laura A. Ferrantini Fusaro). Rio de Janeiro: Garamond, 1999.

. Educação para Todos: o compromisso de Dakar. Brasília: Unesco, Consed, Ação Educativa, 2001. 